\title{
Minute Pulmonary Meningothelial-like Nodules Showing Multiple Ring-shaped Opacities
}

\author{
Masanori Harada ${ }^{1}$, Yuya Aono ${ }^{1}$, Hideki Yasui ${ }^{1}$, Tomohiro Uto ${ }^{1}$, Jun Sato ${ }^{1}$, Shiro Imokawa ${ }^{1}$, \\ Shioto Suzuki ${ }^{2}$, Fumihiko Tanioka ${ }^{2}$ and Takafumi Suda ${ }^{3}$
}

\begin{abstract}
:
Chest computed tomography (CT) findings of minute pulmonary meningothelial-like nodules (MPMNs) usually show tiny nodules (2-5 mm in diameter) of ground-glass attenuation. However, diffuse, thin-walled cavities have rarely been reported. We herein report a 56-year-old woman with MPMNs showing diffuse, thin-walled cystic lesions on a thin-section chest CT scan. Clinicians need to be aware of the imaging characteristics of this conditions to guide appropriate management of lung diseases, as these CT findings may resemble certain metastatic lung neoplasias and primary adenocarcinoma of the lung.
\end{abstract}

Key words: meningotheliomatosis, ground grass opacity, surgical lung biopsy, Turner's syndrome

(Intern Med 58: 3149-3152, 2019)

(DOI: 10.2169/internalmedicine.2108-18)

\section{Introduction}

Minute pulmonary meningothelial-like nodules (MPMNs) are often incidentally detected in surgical or autopsy specimens of the lung during routine pathological examinations (1-7). Recent advances and the increased use of computed tomography (CT) have led to the early detection of this condition. Chest $\mathrm{CT}$ findings of MPMNs usually show tiny nodules $(2-5 \mathrm{~mm}$ in diameter) of ground-glass attenuation (2, 6-13), but diffuse thin-walled cavities have rarely been reported $(8,9)$. We herein report a patient with MPMNs who showed diffuse, thin-walled cystic lesions on thin-section CT of the lungs.

\section{Case Report}

A 56-year-old woman was referred to our hospital for the investigation of a chest X-ray abnormality that was found on a routine medical checkup. She had never smoked and had no family history of cancer. She was generally well, and denied fatigue, cough, shortness of breath or other respiratory symptoms. She had had amenorrhea, but had no cardiovascular diseases.
The physical examination findings were normal except for a slightly short stature. Laboratory findings were also almost normal, including carcinoembryonic antigen, cytokeratin19 and pro-gastrin-releasing peptide levels. Chest CT (Fig. 1) showed randomly distributed, multiple ground-glass opacities measuring up to $5 \mathrm{~mm}$ in diameter. Some of these opacities showed central lucency and appeared ring-like. Magnetic resonance imaging (MRI) of the head and contrast-enhanced CT of the abdomen showed no evidence of malignancy, but the latter revealed a lack of a uterus and ovaries. The blood lymphocyte karyotype was $45, \mathrm{X}$, so a diagnosis of Turner's syndrome was made.

The serum progesterone level was $0.21 \mathrm{ng} / \mathrm{mL}$ (normal range $<0.44 \mathrm{ng} / \mathrm{mL}$ ), and the serum estradiol level was below the detected range. She had never been treated with female hormone-replacement therapy. Positron emission tomography (PET)-CT showed no abnormal uptake of ${ }^{18} \mathrm{~F}$-fluoro-2deoxy-glucose (FDG), except in the thyroid, which was compatible with chronic thyroiditis. The echo-intensity of the thyroid was non-uniform, and the surface was irregular. An echo-guided aspiration biopsy of the thyroid showed no mitotic activity or cytological atypia. Antibodies against thyroglobulin and thyroid peroxidase were found at high concentrations of $388 \mathrm{IU} / \mathrm{mL}$ and higher than $600 \mathrm{IU} / \mathrm{mL}$, re-

${ }^{1}$ Division of Respiratory Medicine, Iwata City Hospital, Japan, ${ }^{2}$ Division of Pathology, Iwata City Hospital, Japan and ${ }^{3}$ Second Division, Department of Internal Medicine, Hamamatsu University School of Medicine, Japan

Received: September 12, 2018; Accepted: May 21, 2019; Advance Publication by J-STAGE: July 22, 2019

Correspondence to Dr. Shiro Imokawa, imokawas@hospital.iwata.shizuoka.jp 


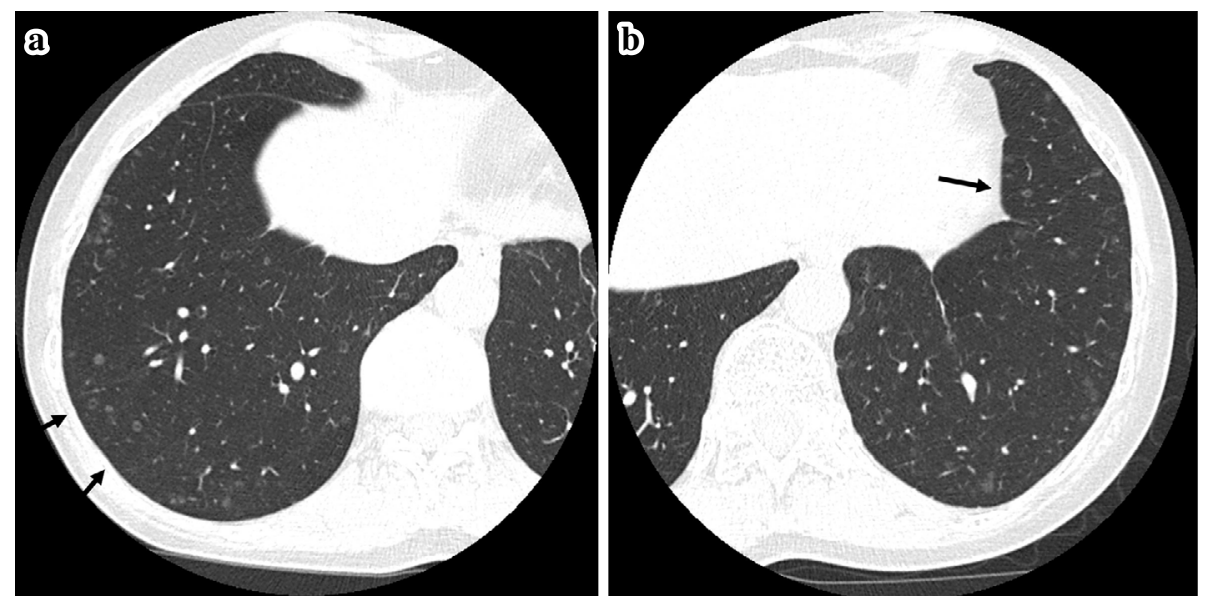

Figure 1. Chest computed tomography (CT) revealed diffuse, multiple ground-glass opacities measuring up to $5 \mathrm{~mm}$ in diameter randomly distributed throughout both lungs (a, b). Some of them showed central lucency (arrows).
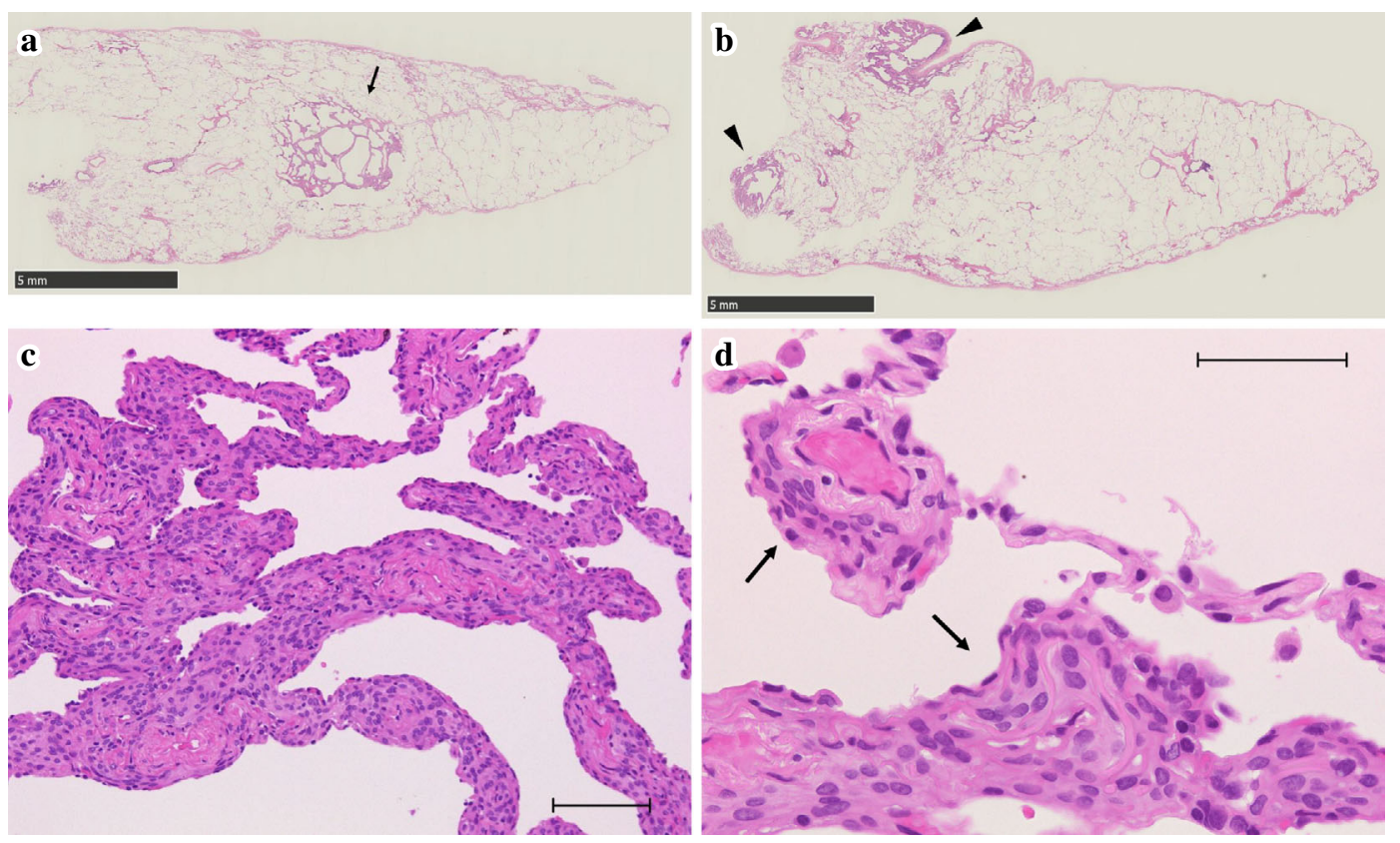

Figure 2. The histological findings of the lung resected by video-assisted thoracic surgery. a: A lowpower photomicrograph of the resected nodule showed interstitial cellular proliferations of uniform round-to-oval cells (arrows). Bar indicates 5,000 $\mathrm{mm}$. b: There is central tissue loss (arrow heads), which correlates with the central lucency on chest CT. Bar indicates 5,000 $\mu \mathrm{m}$. c: A higher-power photomicrograph revealed the bland oval-to-blunted spindle cells infiltrating into the interstitium. Bar indicates $100 \mu \mathrm{m}$. d: Early focus of a meningothelial-like nodule composed of small clusters of meningothelial cells in the interstitium (arrows). Bar indicates 50 $\mu \mathrm{m}$.

spectively. Therefore, a diagnosis of chronic thyroiditis was made.

The serum level of thyroid-stimulating hormone (TSH), free $\mathrm{T} 3$ and $\mathrm{T} 4$ were within the normal respective ranges. A lung metastatic tumor of unknown primary lesions was suspected, so video-assisted thoracic surgery was performed. The histological findings (Fig. 2) showed nodular lesions with interstitial proliferation of uniform, round to oval cells with variable widening of the alveolar septa. Some nodules had central airspace lesions, that might have been associated with the findings of ring-like opacity on chest CT.

Immunohistochemistry was positive for epithelial membrane antigen, vimentin, progesterone receptor, and CD56 (Fig. 3). The diagnosis of MPMNs was ultimately made (1-4). Follow-up chest CT eight months after the diagnosis showed no change in morphologic characteristics, and the patient was free of symptoms. 

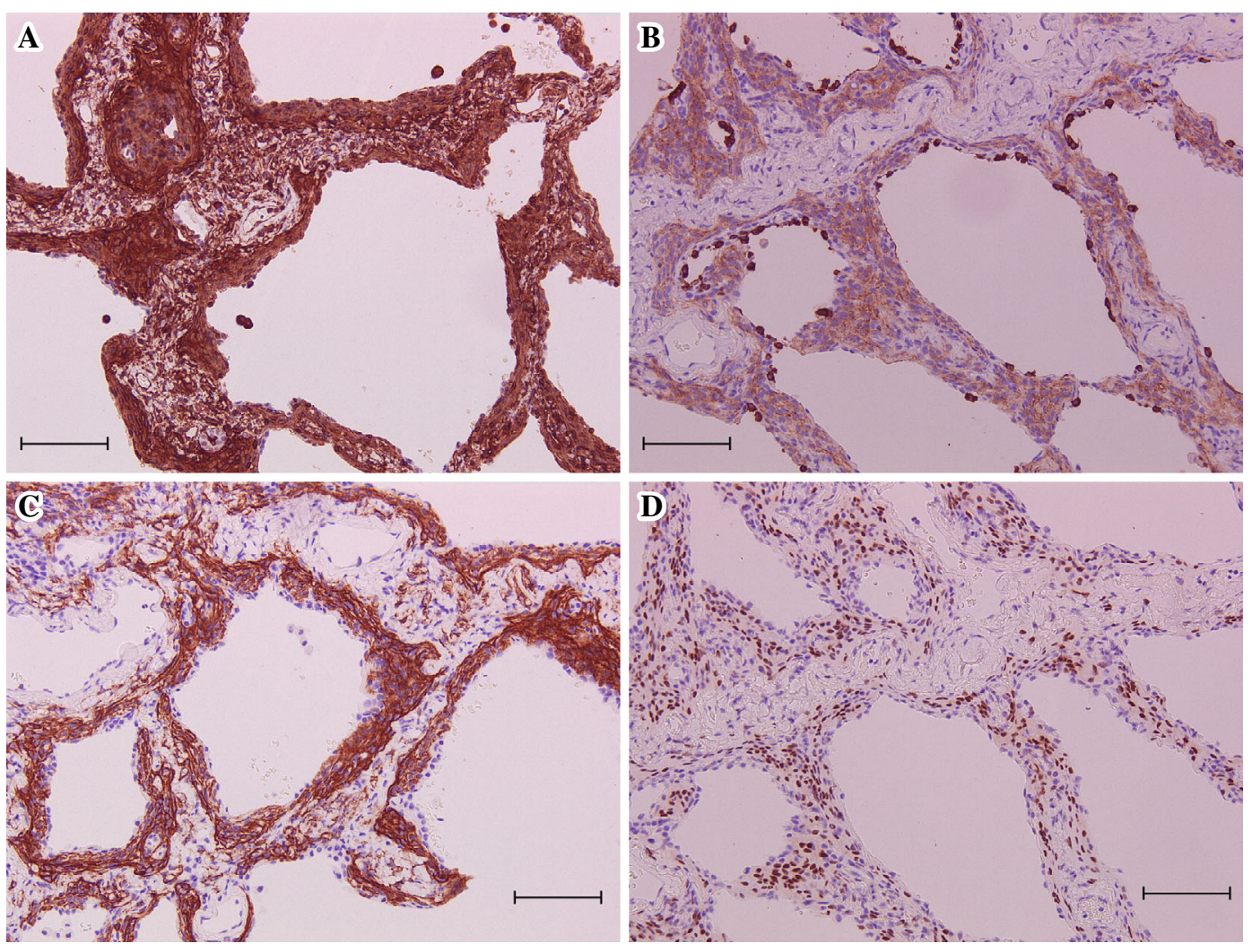

Figure 3. Immunohistochemical staining was positive for vimentin (A), epithelial membrane antigen (B), CD56 (C) and progesterone receptor (D). These findings are consistent with meningotheliallike nodules. Bar indicates $100 \mu \mathrm{m}$.

Table. Literature Review of Chest CT Findings in Patients with MPMNs.

\begin{tabular}{|c|c|c|c|c|c|c|}
\hline Case & 1 & 2 & 3 & 4 & 5 & 6 \\
\hline $\begin{array}{l}\text { Refference } \\
\text { No. }\end{array}$ & 8) & 13) & 9) & 11) & 10) & 12) \\
\hline Age/Sex & $54 / \mathrm{F}$ & $64 / \mathrm{F}$ & $59 / \mathrm{F}$ & $55 / \mathrm{F}$ & $52 / \mathrm{M}$ & $54 / \mathrm{F}$ \\
\hline $\begin{array}{l}\text { Chest CT } \\
\text { findings }\end{array}$ & $\begin{array}{l}\text { multiple, bilateral, } \\
\text { randomly } \\
\text { distributed, } \\
1 \text { - to- } 4 \mathrm{~mm} \\
\text { nodules, thin wall } \\
\text { cavities(+) }\end{array}$ & $\begin{array}{l}\text { numerous } \\
\text { micronodules, } \\
\text { upper lobe } \\
\text { predominance, } \\
\text { under } 3 \mathrm{~mm} \text { in } \\
\text { diameter }\end{array}$ & $\begin{array}{l}\text { multiple minutes } \\
\text { nodules, random } \\
\text { distribution, poorly } \\
\text { defined, cotton wool } \\
\text { appearance, several } \\
\text { were cavitated }\end{array}$ & $\begin{array}{c}\text { tiny nodules of } \\
\text { ground ground-glass } \\
\text { attenuation, } 1-3 \mathrm{~mm} \\
\text { in diameter }\end{array}$ & $\begin{array}{c}\text { well difined } \\
\text { nodule of } 11.3 \mathrm{~mm} \\
\text { in diameter and } \\
\text { multiple small } \\
\text { nodules of various } \\
\text { size in both lungs }\end{array}$ & $\begin{array}{l}\text { multiple small } \\
\text { nodules, } \\
\text { bilateral lung } \\
\text { field }\end{array}$ \\
\hline
\end{tabular}

\section{Discussion}

Chest CT findings of MPMNs (2, 6-13) reportedly show diffuse bilateral pulmonary nodules and/or tiny ground-glass attenuation. Table shows the literature review of the chest CT findings in patients with MPMNs, which have been reported precisely. These CT findings are nonspecific, and differential diagnoses include metastatic lung neoplasia, primary adenocarcinoma of the lungs and military tuberculosis. Our case was rare in that chest CT showed multiple, bilateral, randomly distributed tiny ground glass nodules, some of which showed central lucency, appearing as ring-shaped opacities. Such chest CT findings have been reported in only two other cases $(8,9)$. Although MPMNs are incidental pathological findings of no clinical significance, recent ad- vances and the increased use of chest CT will increase the likelihood of such minute lesions being detected. Clinicians should therefore be aware of the imaging characteristics of this conditions in order to guide the appropriate management of lung diseases.

As reported previously, our case showed the early focus of meningothelial-like nodule composed of small clusters of meningothelial cells in the interstitium (1-5). Extension of the lesion along the alveolar walls may have resulted in the ground-glass opacities seen on thin-section CT. Our case had many nodules with central radiological lucency on chest CT. The mechanisms by which these ring-like nodules form are unclear at present. We speculate that extension of meningothelial cells along the alveolar septa may destroy the alveolar wall, but further investigations, including assessments of the radiological and pathological co-relations, are needed. 
The majority of patients with MPMNs were encountered in their 60s, and were predominantly women, associated with a variety of diseases, including chronic lung diseases, lung cancer, congestive heart failure and thromboembolism $(1-3,6,7)$. Shimaoka et al. reported a case of this condition associated with Turner' syndrome with a history of female hormone-replacement therapy, in which chest CT showed multiple small nodular shadows in the bilateral lung fields (12). Our case had not received this therapy, as these two conditions were diagnosed concomitantly.

The origin and nature of MPMNs remain unclear at present. Several studies have suggested that chronic lung diseases may stimulate the lungs to induce the formation of MPMNs by stretching or stiffening the alveolar septa, or by inducing hypoxia, ischemia, parenchymal distortion, or some combination of these factors $(1,3,10)$. However, our case did not have any chronic lung diseases. Of note, MPMNs are observed more often in women than in men, and more than half of MPMNs show immunoreactivity for progesterone receptors $(3,4)$. Based on these findings, it is also speculated that some hormonal imbalance, such as progesterone stimulation, may provide a cellular growth advantage to MPMNs. Our case also showed immunoreactivity for progesterone receptor. However, the precise mechanisms involved are unclear, and further investigations are needed to clarify this point.

MPMNs are usually thought to run a benign course, and conservative treatment is favored $(2,8-12)$. However, based on the findings of a loss of heterogeneity-based genotyping analysis, it is speculated that MPMNs may represent the transition between a reactive and neoplastic process (14). Mizutani et al. reported that MPMNs were found more often in patients with malignant pulmonary tumors than in those with benign diseases (5). Based on these findings, a workup for undiagnosed malignancy is warranted when MPMNs are discovered.

Author's disclosure of potential Conflicts of Interest (COI). Takafumi Suda: Honoraria, Boehringer Ingelheim.

\section{References}

1. Gaffey MJ, Mills SE, Askin FB. Minute pulmonary meningothelial-like nodules. A clinicopathologic study of so-called minute pulmonary chemodectoma. Am J Surg Pathol 12: 167-175, 1988.

2. Suster S, Moran CA. Diffuse pulmonary meningotheliomatosis. Am J Surg Pathol 31: 624-631, 2007.

3. Mukhopadhyay S, El-Zammar OA, Katzenstein AL. Pulmonary meningothelial-like nodules: new insights into a common but poorly understood entity. Am J Surg Pathol 33: 487-495, 2009.

4. Niho S, Yokose T, Nishiwaki Y, Mukai K. Immunohistochemical and clonal analysis of minute pulmonary meningothelial-like nodules. Hum Pathol 30: 425-429, 1999.

5. Mizutani E, Tsuta K, Maeshima A, Asamura H, Matsuno Y. Minute pulmonary meningothelial-like nodules: clinicopathological analysis of 121 patients. Hum Pathol 40: 678-682, 2009.

6. Asakawa A, Horio H, Hishima T, Yamamichi T, Okui M, Harada M. Clinicopathological features of minute pulmonary meningothelial-like nodules. Asian Cardiovasc Thorac Ann 25: 509-512, 2017.

7. Gleason JB, Valentin R, Almedia P, Martinez N, Bejarano PA. Diffuse pulmonary meningotheliomatosis: a literature review of a rare diffuse parenchymal lung disease with unclear clinical significance. J Assoc Chest Physic 5: 18-25, 2017.

8. Kraushaar G, Ajlan AM, English JC, Muller NL. Minute pulmonary meningothelial-like nodules: a case of incidentally detected diffuse cystic micronodules on thin-section computed tomography. J Comput Assisted Tomog 34: 780-782, 2010.

9. Mora RB, Nieto JMS, $\mathrm{Hu} \mathrm{C}$, Mateos EA, Bascunana AG, Rodriguez MR. Diffuse pulmonary meningotheliomatosis diagnosed by transbronchial lung biopsy. Respiration 86: 145-148, 2013.

10. Lee SK, Kim GJ, Kim YJ, et al. Minute pulmonary meningothelial-like nodules simulating hematogenous lung metastasis: a case report. Tuberc Respir Dis 75: 67-70, 2013.

11. Kuroki M, Nakata $H$, Masuda $T$, et al. Minute pulmonary meningothelial-like nodules: high-resolution computed tomography and pathologic correlations. J Thorac Imag 17: 227-229, 2002.

12. Shimaoka $Y$, Ichikawa $H$, Ohara $T$, Asakawa $K$, Terada $M$, Toyama J. A case of diffuse pulmonary meningotheliomatosis. AJRS 3: 695-699, 2014.

13. Sellami D, Gotway MB, Hanks DK, Webb WR. Minute pulmonary meningothelial-like nodules: thin-section CT appearance. 25: 311-313, 2001.

14. Ionescu DN, Sasatomi E, Aldeeb D, et al. Pulmonary meningothelial-like nodules. A genotypic comparison with meningiomas. Am J Surg Pathol 28: 207-214, 2004.

The Internal Medicine is an Open Access journal distributed under the Creative Commons Attribution-NonCommercial-NoDerivatives 4.0 International License. To view the details of this license, please visit (https://creativecommons.org/licenses/ by-nc-nd/4.0/).

\footnotetext{
(C) 2019 The Japanese Society of Internal Medicine Intern Med 58: 3149-3152, 2019
} 